\title{
Svalbard astroclimate research: expedition and first results
}

\author{
Grigoriy Bubnov $^{1,2}$, V.F. Vdovin ${ }^{1,2}$, P.M. Zemlyanukha ${ }^{1}$,V.S. Okunev ${ }^{1}$, V.F. Grigor'yev ${ }^{3}$ \\ ${ }^{1}$ Institute of Applied Physics RAS, N.Novgorod, Russia, bubnov@ieee.org \\ ${ }^{2}$ Nizhny Novgorod State Technical University n.a. R.E. Alekseev, N.Novgorod, Russia \\ ${ }^{3}$ Polar Geophysical Institute RAS, Murmansk, Russia
}

\section{Expedition and equipment}

This paper deals with the actual results of astroclimate investigations in mm-waveband on Svalbard archipelago. The investigations have begun in June 2018 and are still ongoing. We use the dual-wave radiometric system operating by atmospheric-dip method to estimate an optical depth in $2 \mathrm{~mm}$ and $3 \mathrm{~mm}$ atmospheric windows [1]. It has been installed on the polar station of Polar Geophysical Institute near Barentsburg town, Svalbard. (78 5'42.22"N; 14¹2'35.98"E) Remote control system allows to collect data via Internet.

It is also equipped with a makeshift meteostation and anti-icing heater, which is applied in autonomous field experiment for the first time. The meteostation provides a brightness temperature measurement of the sky by IR sensor, apart from typical meteo-data (eg. temperature, pressure, humidity). It allows to define a cloudiness by empiric methodic. Cloudiness calculation methodic is based on work [2,3]. The essence of methodic is to define the difference between real air temperature and brightness temperature by IR-sensor MLX90614. The more this difference is, the less clouds are in air and vice versa; the difference more than $20 \mathrm{~K}$ corresponds a clear sky conditions, while the difference less than $5 \mathrm{~K}$ means overcast weather.

As is known, the atmospheric-dip method can't be used in overcast conditions. The new data processing method, which is firstly applied in 2018 [4], allows to save some part of data, measured in overcast conditions. Resulting optical depth includes absorption in stratus clouds as well. Picture 1 shows 5-day record of optical depth $\tau$ (Nep) vs temperature difference dT (K). Increasing difference dT between physical air temperature and IR brightness temperature means more clear sky conditions in July 16. This is also accompanied by decreasing mm-wave Optical depth values.

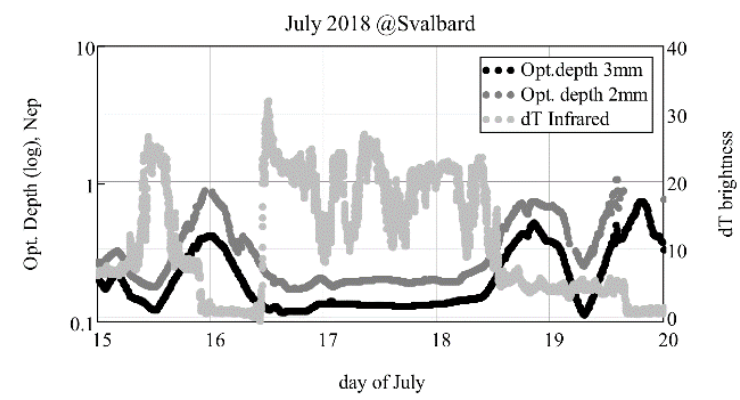

Fig. 1. MM-wave optical depth (log scale) vs temperature difference by IR sensor.

\section{Optical depth and PWV}

One of the most important result is an optical depth statistic, which is measured by our "MIAP-2" setup. A cumulative distribution shown below are representing the month-averaged optical depth values. We can characterize the astroclimate on Svalbard as poor for $\mathrm{mm}$ wave observations in Summer period.
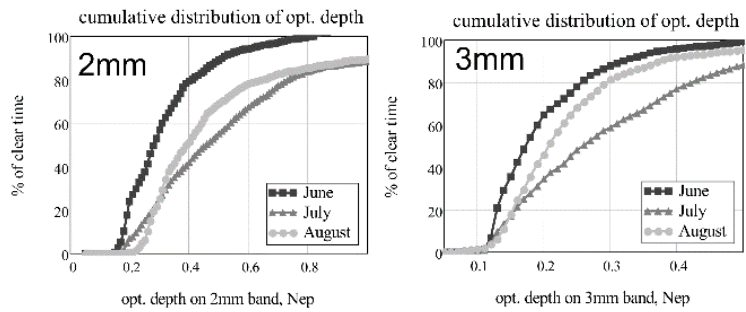

Fig. 2. Cumulative distribution of Optical depth in $2 \mathrm{~mm}$ and $3 \mathrm{~mm}$ atmospheric windows in Summer.

Such high values of optical depth are mostly due to high air humidity values and cloudiness. It is usually correlated in time (see pic.3).

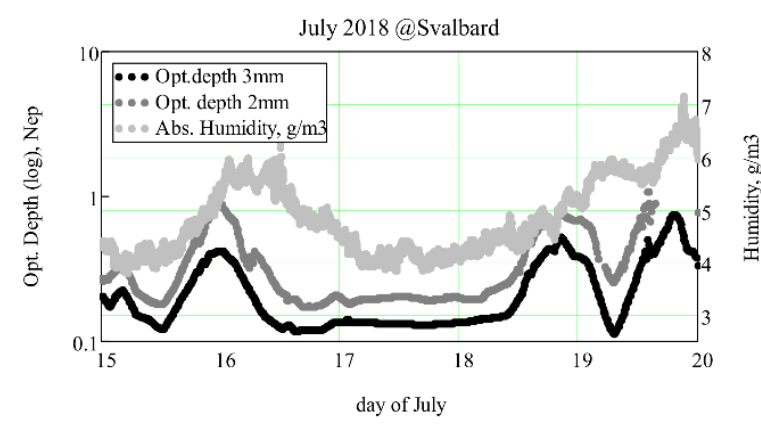

Fig. 3. MM-wave optical depth (log scale) vs Absolute humidity.

Since 2012 we have provided s several expeditions on astroclimate research, so now we can compare these places by month-median values (see pic. 4). Current Svalbard measurements are not promising, but the fullyear result remains to be seen.

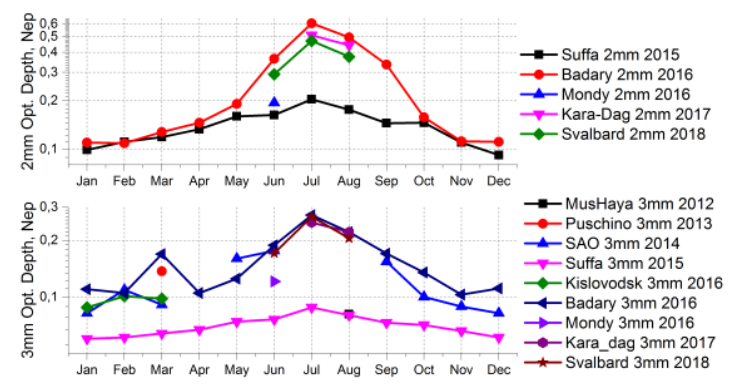

Fig. 4. MM-wave optical depth (log scale) in different places over the Eastern Hemisphere measured by MIAP-2 setup.

Knowing the Optical depth, it is easy to calculate the PWV (mm) [1,4]. The PWV values obtained below (Fig.5) includes a condensed water as well as water vapor by MIAP-2, but not for measurements in [5]. The 
data given in [5] obtained by Bouger method. It means that precipitable water is measured only in sunny days, and thus, it has a few statistics. It is the reason why these values are about $80 \%$ higher than presented in [5].

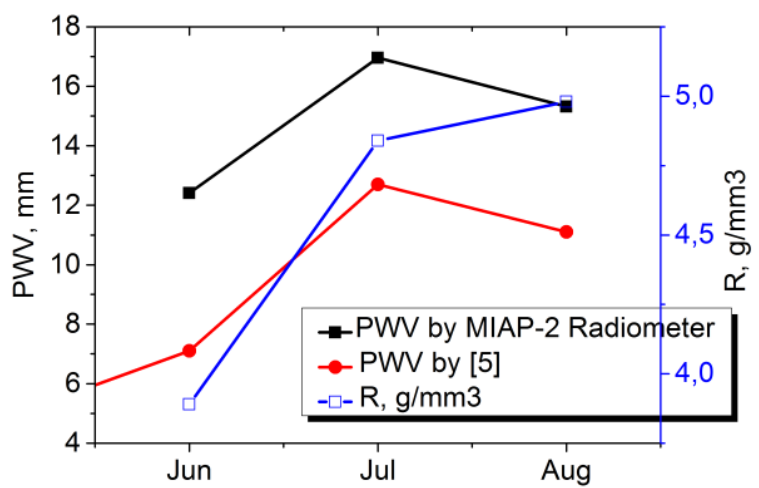

Fig. 5. Precipitable water vapor and relative humidity on Svalbard in Summer.

Using the data obtained by MLX90614 IR sensor in meteostation, it is possible to calculate the cloudiness statistics. The reference points of temperature difference were chosen as: $\leq 18 \mathrm{~K}$ for Overcast, from 18 to $27 \mathrm{~K}$ - Cloudy and upper than 27 - for Clear sky conditions. The obtained results are generally consistent with meteorological observations [6].

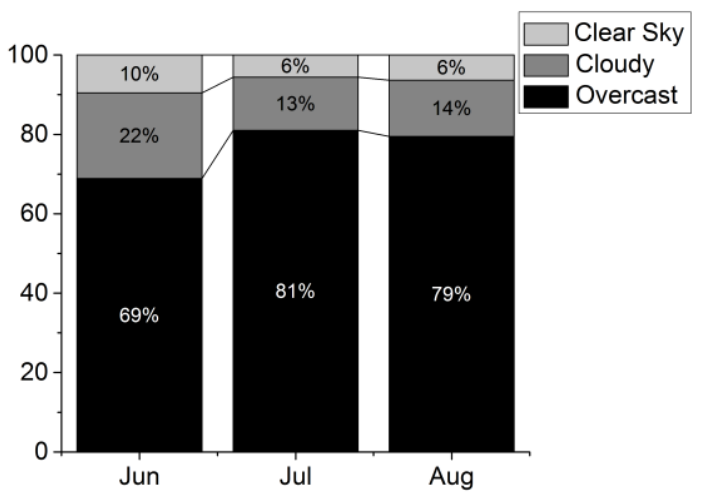

Fig. 6. Cloud statistics by IR sensor.
In conclusion we have to characterize Svalbard as non-suitable for mm-wave radioastronomy at least in summer period. The winter period approaching soon and inspires a hope to be much better due to low temperatures. Another important result is a good reliability of equipment: it routinely works for 3 months without any assistance. The makeshift Arduino-based meteostation gives a satisfying result. We will continue measurements in Barentsburg till June 2019 to close the year-cycle.

\section{Acknowledgements}

This work has been made with particularly financial support from IEEE APS Eugene F. Knott Memorial Doctoral Research Grant, as well as the scholarship issued by RF President [CП-5103.2018.3.]. The authors would like to grateful Oleg Kutkov and Sergey Nazarov from Krimean Astrophysical Observatory for helpful advice [3] and S.M. Sakerin, D.M. Kabanov from Institute of Atmospheric Optics of RAS for provided data. Special thanks for Barentsburg staff Yu.A. Kvashnin, V.G. Kuleshov and J.D. Mishakova for help in expedition.

\section{References}

1. V. I. Nosov, O. S. Bolshakov et al. A dual-wave atmosphere transparency radiometer of the millimeter wave range. // Instruments and Experimental Techniques. May 2016, Vol 59, Issue 3, pp 374-380. DOI: 10.1134/ S0020441216020111

2. Nazarov, S. V., Kutkov, O. E. Infrared cloud sensor at $\mathrm{CrAO} / /$ Proc. of $47^{\text {th }}$ International student scientific conference, Yekaterinburg. 2018. p.261. ISBN:978-5-7996-2283-1

3. [online] http://olegkutkov.me/2017/08/10/mlx90614raspberry

4. G.M. Bubnov, V.F. Vdovin, P.M. Zemlyanukha and I.I. Zinchenko. A refined method of the data processing for astroclimate measurements in mm-waves. // Proc. of 29th IEEE International Symposium on Space Terahertz Technology, Pasadena, California, USA, March 26-28, 2018.

5. S.M. Sakerin, D.M. Kabanov et al. Generalization of Results of Atmospheric Aerosol Optical Depth Measurements on Spitsbergen Archipelago in 2011-2016 // Atmospheric and Oceanic Optics, 2018, Vol. 31, No. 2, pp. 163170.

6. [online] www.meteoblue.com 